\title{
A fisheye lens as a photonic Doppler velocimetry probe
}

\author{
Brent C. Frogget \\ Optical Engineer \\ Presentation to \\ SPIE, San Diego Conference
}

August 16, 2012

This work was done by National Security Technologies, LLC, under Contract No. DE-AC52-06NA25946 with the U.S. Department of Energy. 


\section{Participants \\ (Partial List)}

Brent C. Frogget, Brian M. Cata, Brian C. Cox, Douglas O. DeVore, David L. Esquibel, Daniel K. Frayer, Morris I. Kaufman, Robert M. Malone, Vincent T. Romero National Security Technologies, LLC, Los Alamos Operations

\section{Michael R. Furlanetto, David B. Holtkamp \\ Los Alamos National Laboratory}




\section{Topics}

- Background

- Other Probe Types

- Fisheye Lens Photonic Doppler Velocimetry (PDV) Probe

- Improvements

- Summary 


\section{PDV Description}

Concept: Generate a beat signal using fiber mixing of unDoppler-shifted light with Doppler-shifted light and measure beat frequency.

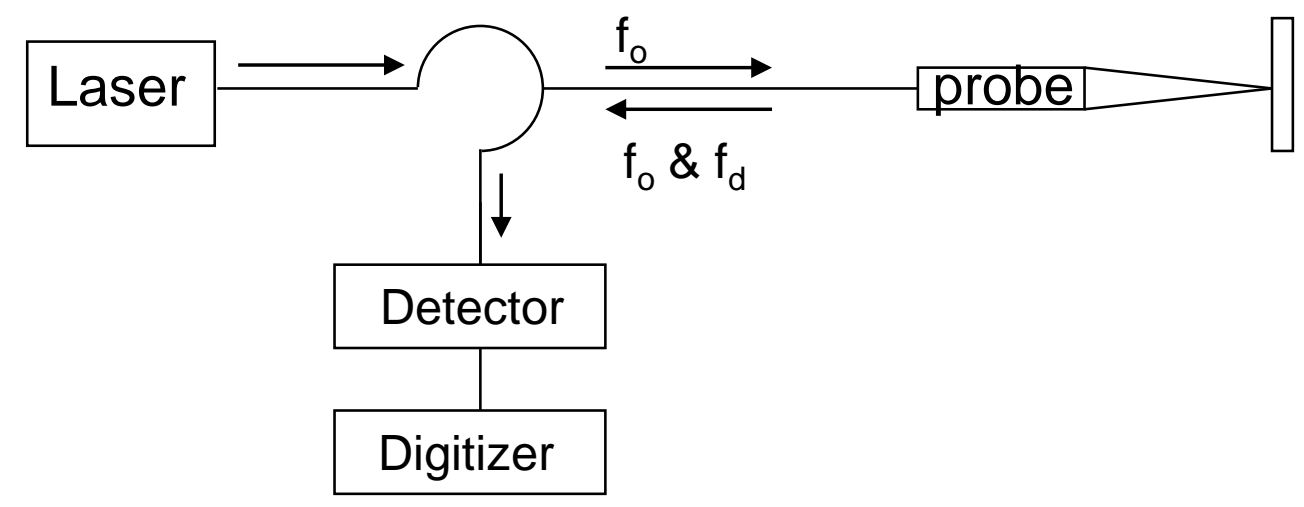

Fourier transform
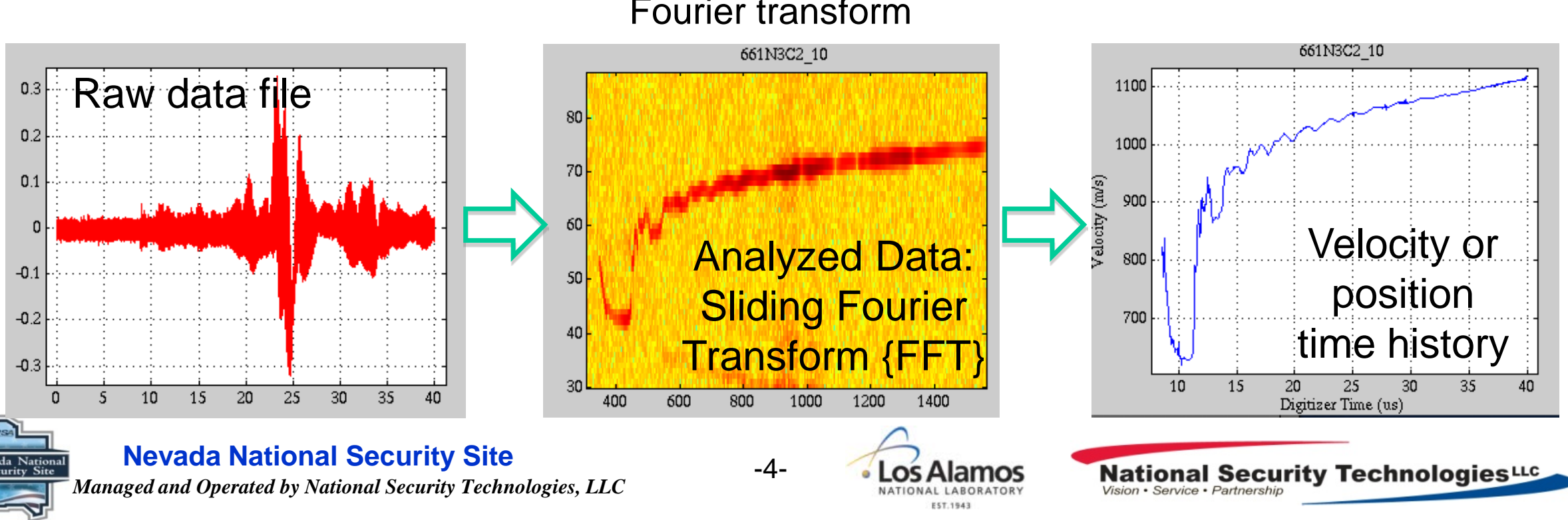

Nevada National Security Site

Managed and Operated by National Security Technologies, LLC Est:1943 


\section{Example Electrical Pin Domes}
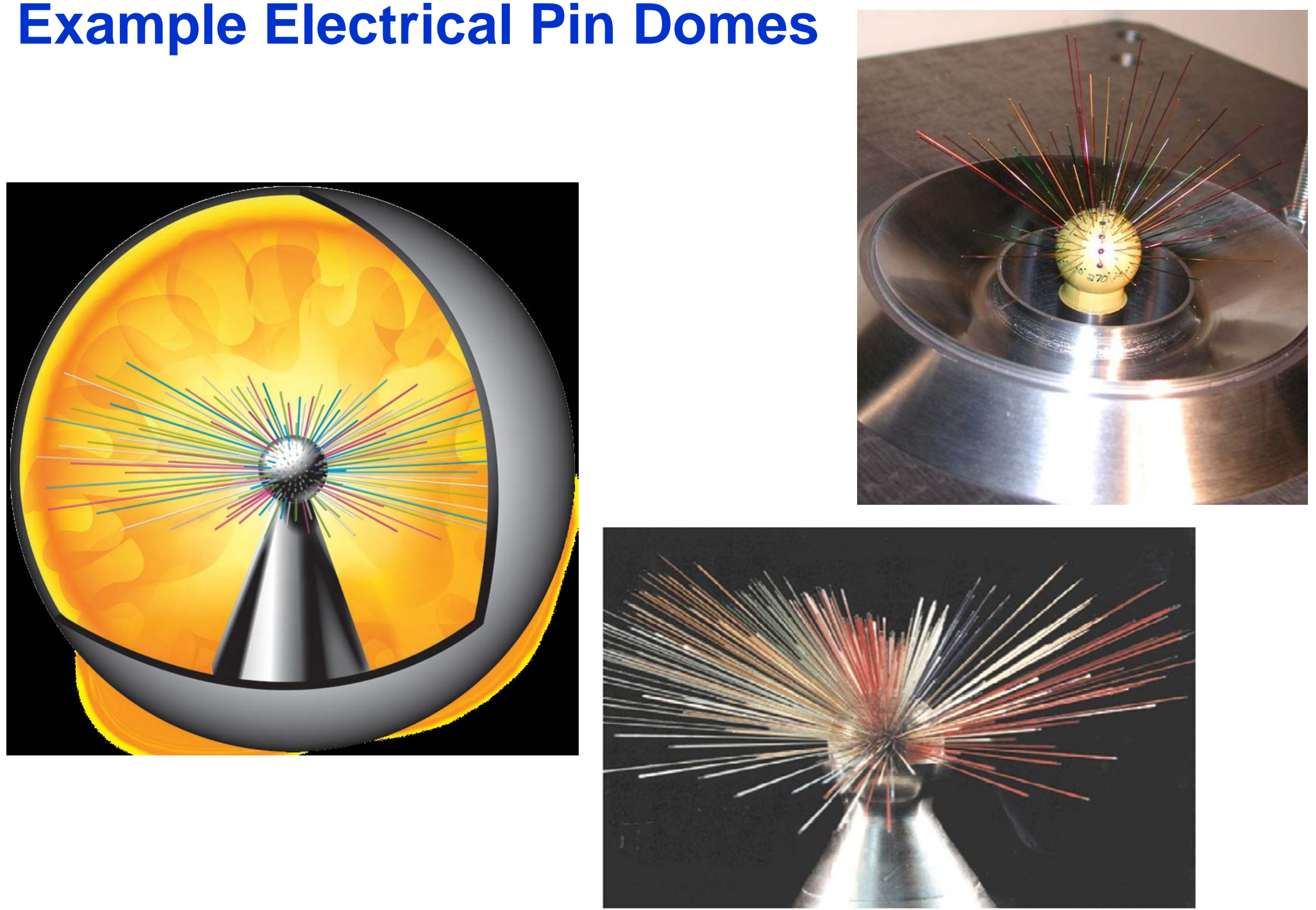

Nevada National Security Site Managed and Operated by National Security Technologies, LLC

-5- $\int_{\text {National LaBoratoRY }}$

$\underset{\text { Vision. Senvice. Partnership }}{\text { National Technologies LLC }}$ (5, 1.34 


\section{Discrete Collimator Multipoint Ball Probe}
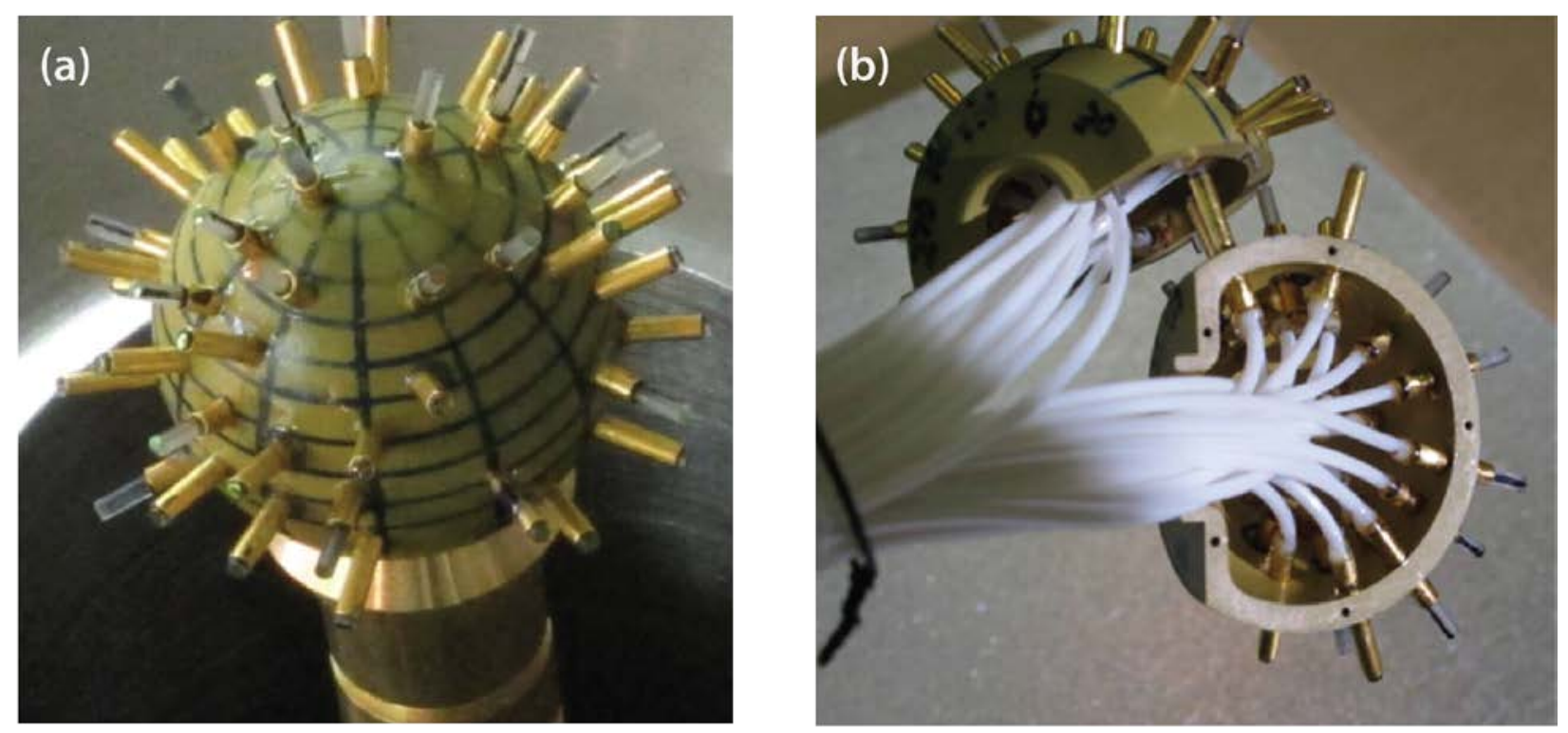

(a) Assembled discrete ball probe

(b) Opened discrete ball probe showing large jacketed fibers

Even with smaller jacketed optical fibers, the small package size limits the number of points that can be added

$-6-$

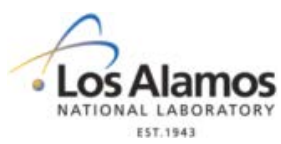




\section{Example Eyepiece Type Lens Ray Trace}

To get to higher angles, lenses must 'wrap around' pupil

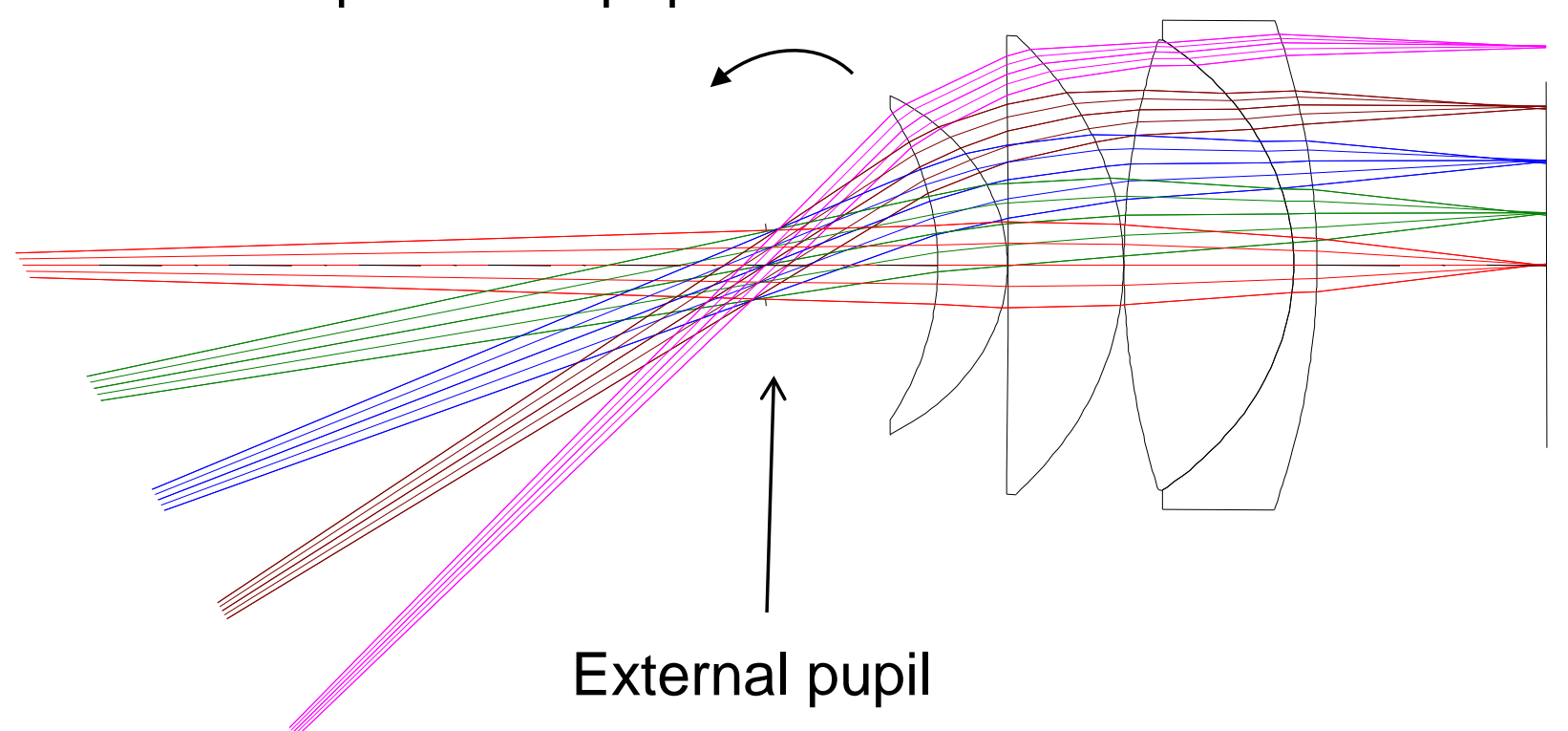




\section{Multiple Lens Array Probe}
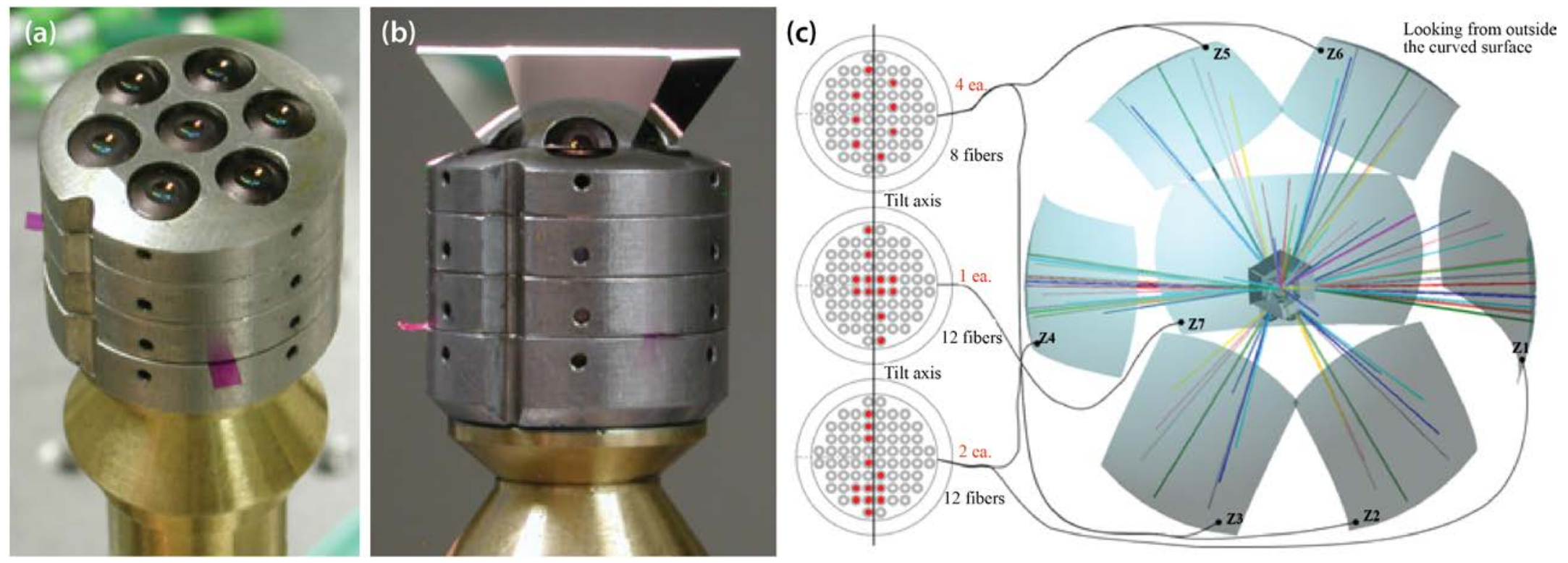

(a) Without multi-faceted prism

(b) With prism

(c) Fiber points in zone coverage (zone positions can be changed if prism face angles are changed)

$-8-$

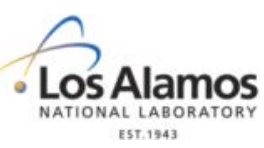




\section{Example Fisheye Lens Ray Trace}

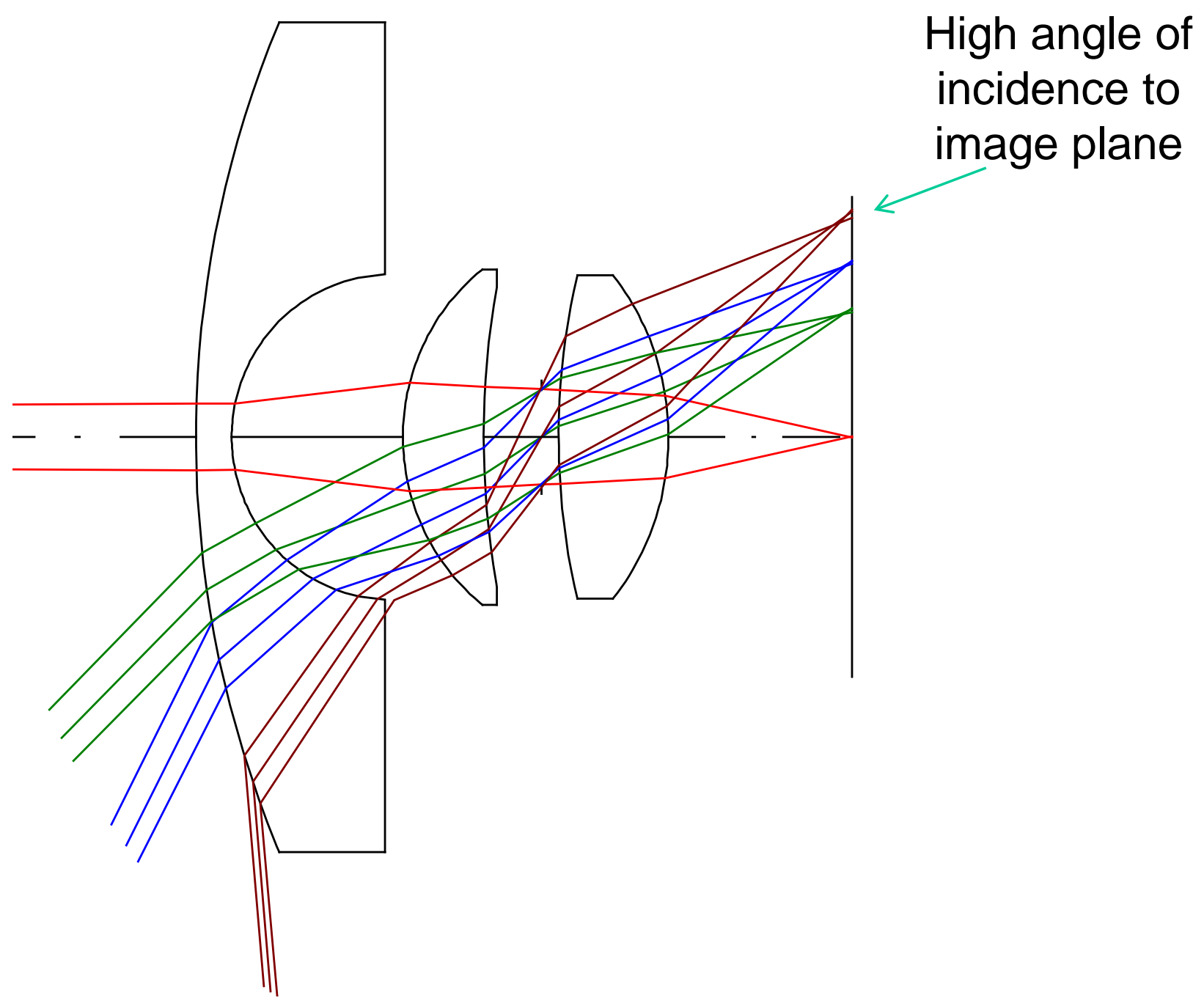




\section{PDV Fisheye Lens Ray Trace}

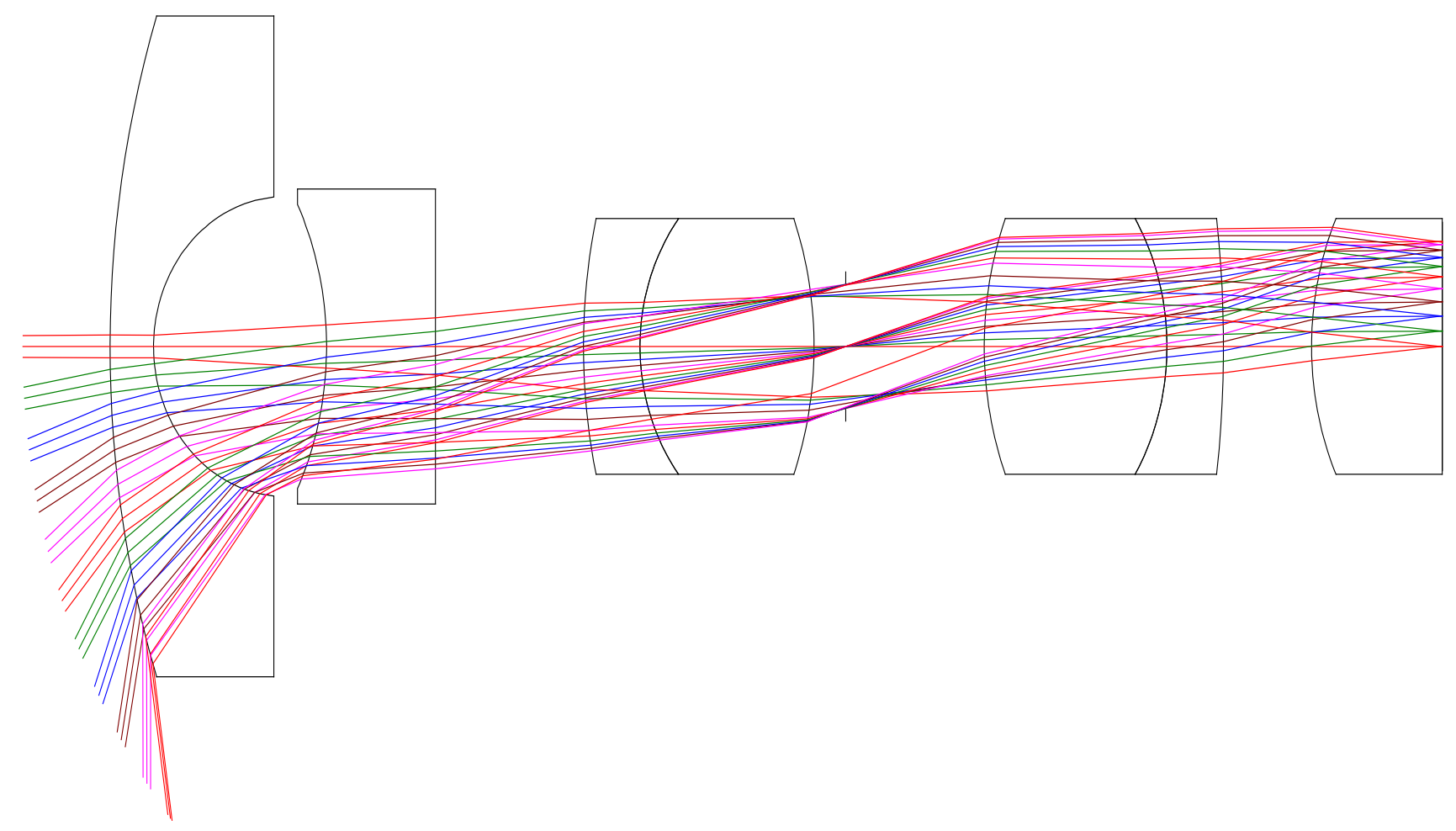




\section{PDV Fisheye Lens Ray Trace - Features}

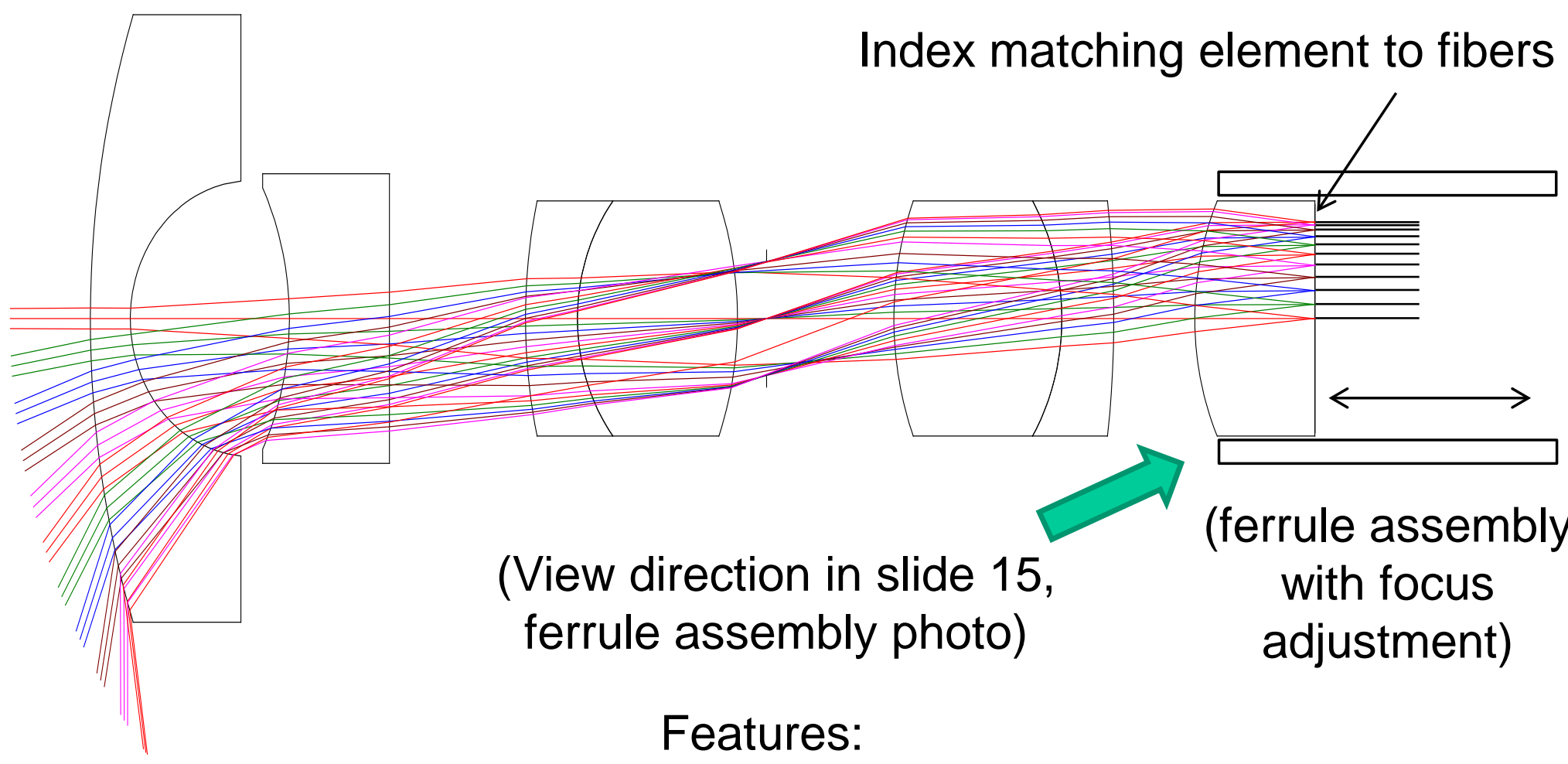

- $\quad$ Light incident normal to optical fibers

- Index match to optical fibers to reduce back reflections

- Distance from index-matched element and fibers can be adjusted for fine focusing

- Needs good anti-reflection lens element coatings and limited number of elements 


\section{PDV Fisheye Lens}

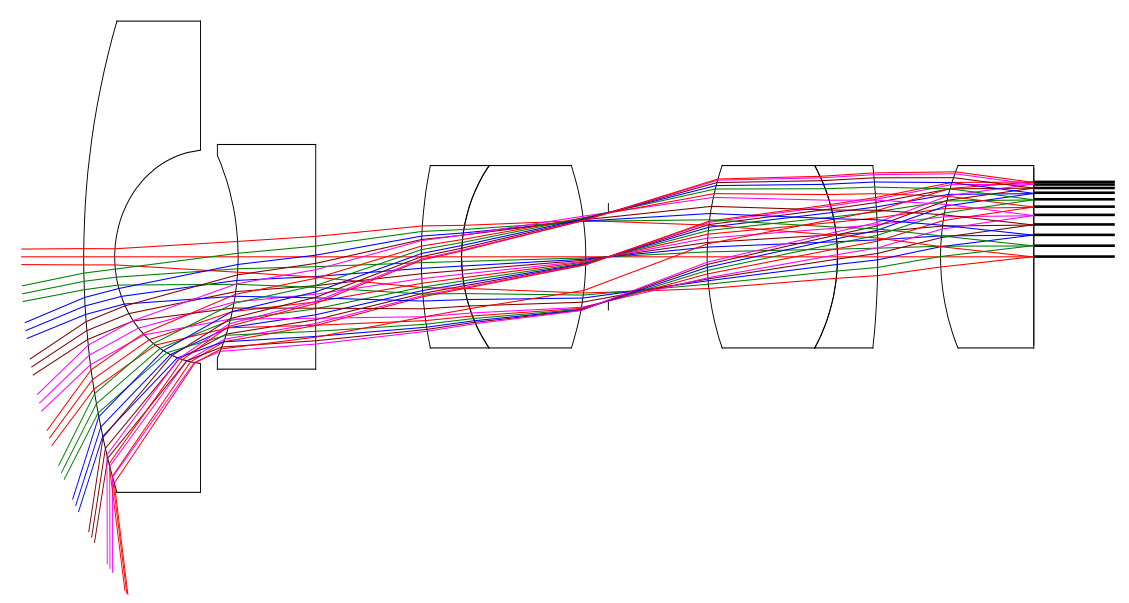

- Disadvantages

- This lens type has some distortion at the edge of the field of view. This causes a change in measurement point spacing with angle-high-angle spots become elliptical and less efficient.

- The fiber plane is a non-standard size compared to commercial array connectors and is custom made. 


\section{PDV Fisheye Lens}

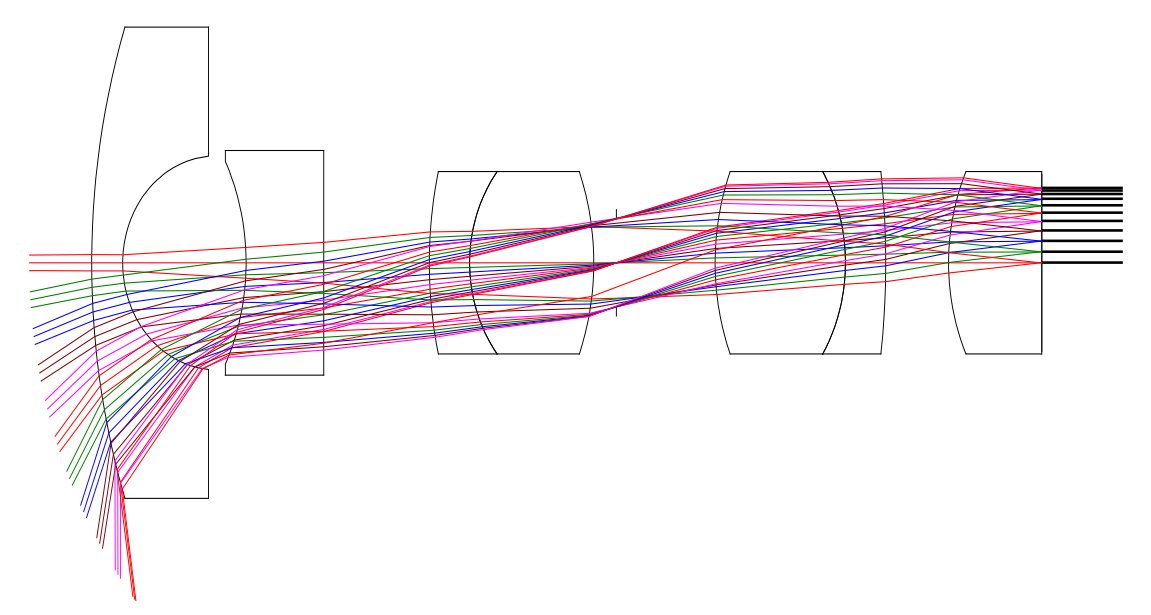

- Advantages

- A 'fisheye' lens can image measurement points over more than a hemisphere without 'dead' regions

- The front fisheye element encroaches very little into the center of the cavity, allowing for longer tracking distances

- This design uses an index-matching element to keep all fibers at the same plane without high return loss 


\section{Fiber Ferrule Stuffed with Single-Mode Optical Fibers}

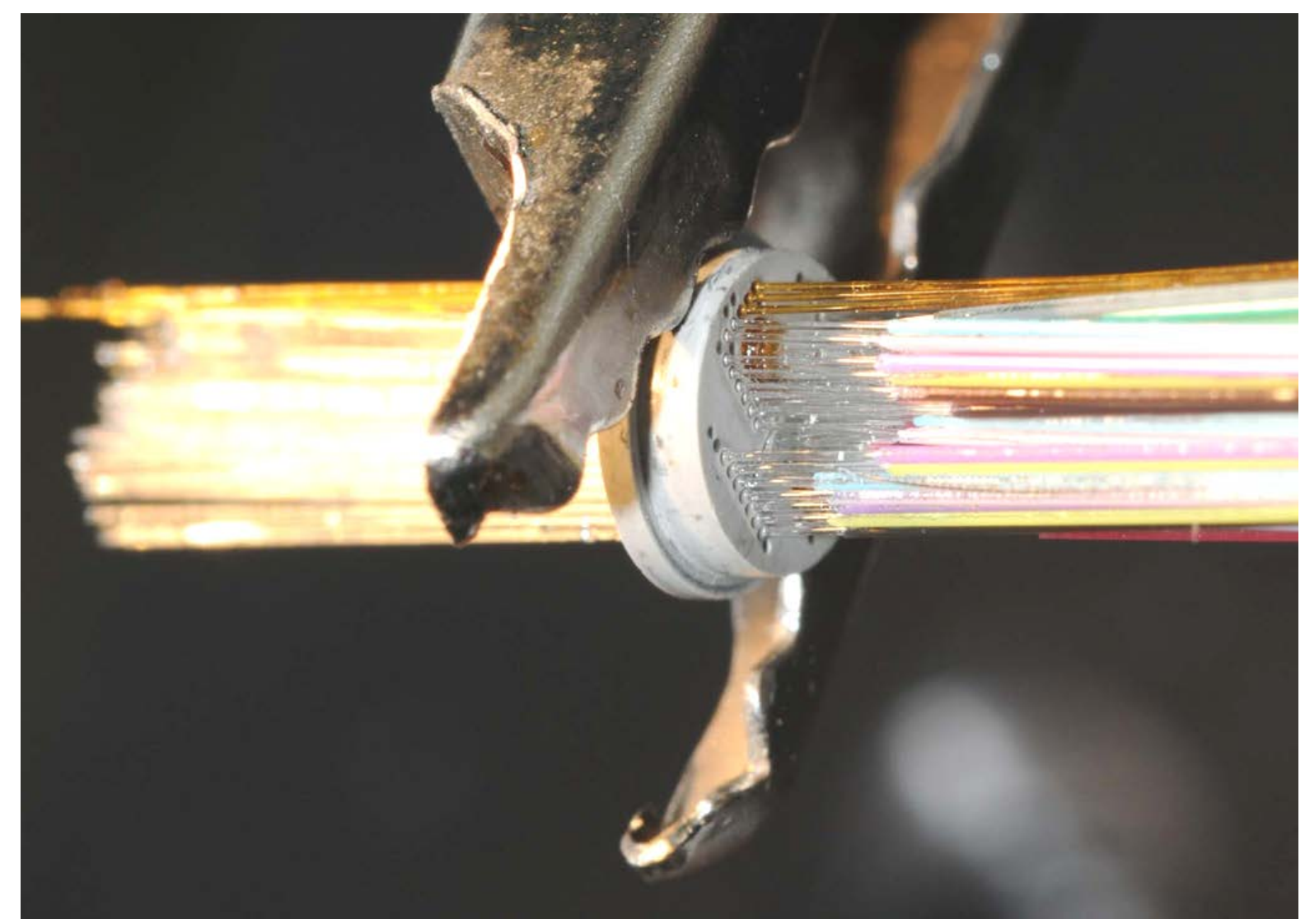

Nevada National Security Site Managed and Operated by National Security Technologies, LLC
$-14-$

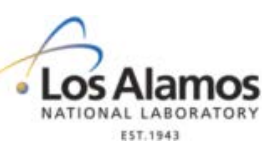

National Security Technologies LLC 


\section{Fisheye Probe Ferrule and Lens Assembly}

(View direction in slide 11)

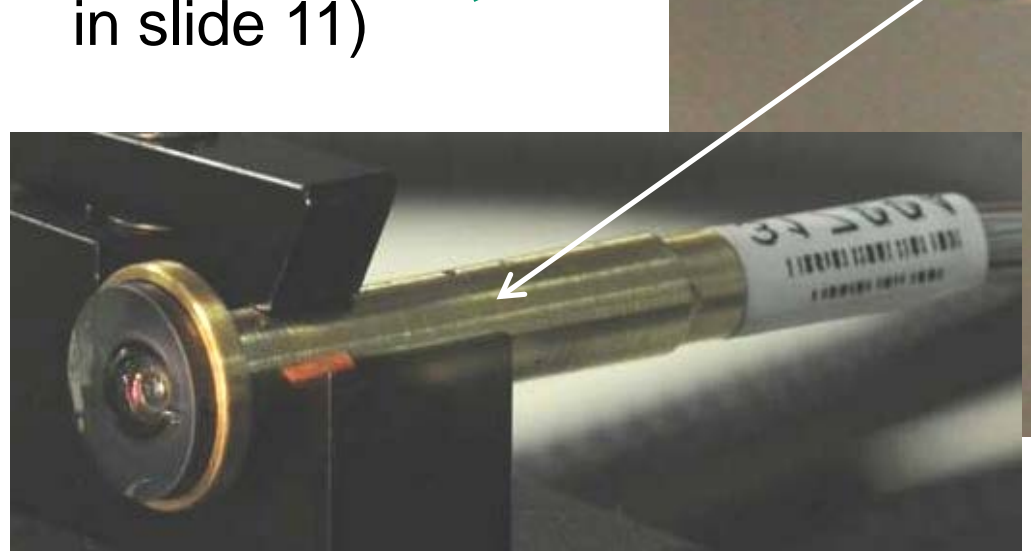

Tip shown is about halfway down tube at left; the inner tube slides in or out to adjust

$-15-$

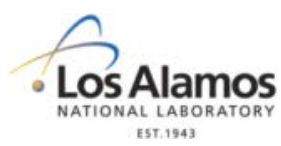




\section{Lessons Learned}

- Good 1550-nanometer anti-reflection coatings needed on lenses

- Index-matching gel works better than index-matching epoxy

- Fiber polishing for coupling to index-matching element is sensitive

- Focusing to best position is sensitive and best done actively using an IR camera

- Highest angle points are less efficient due to distortion and coatings

- The fiber bundle can be put through the blast tube before attaching it to the lenses, so fiber connectors do not need to be cut 


\section{Fisheye Rough-Angle Metrology}

This rough measurement is done inside a rapid prototype dome

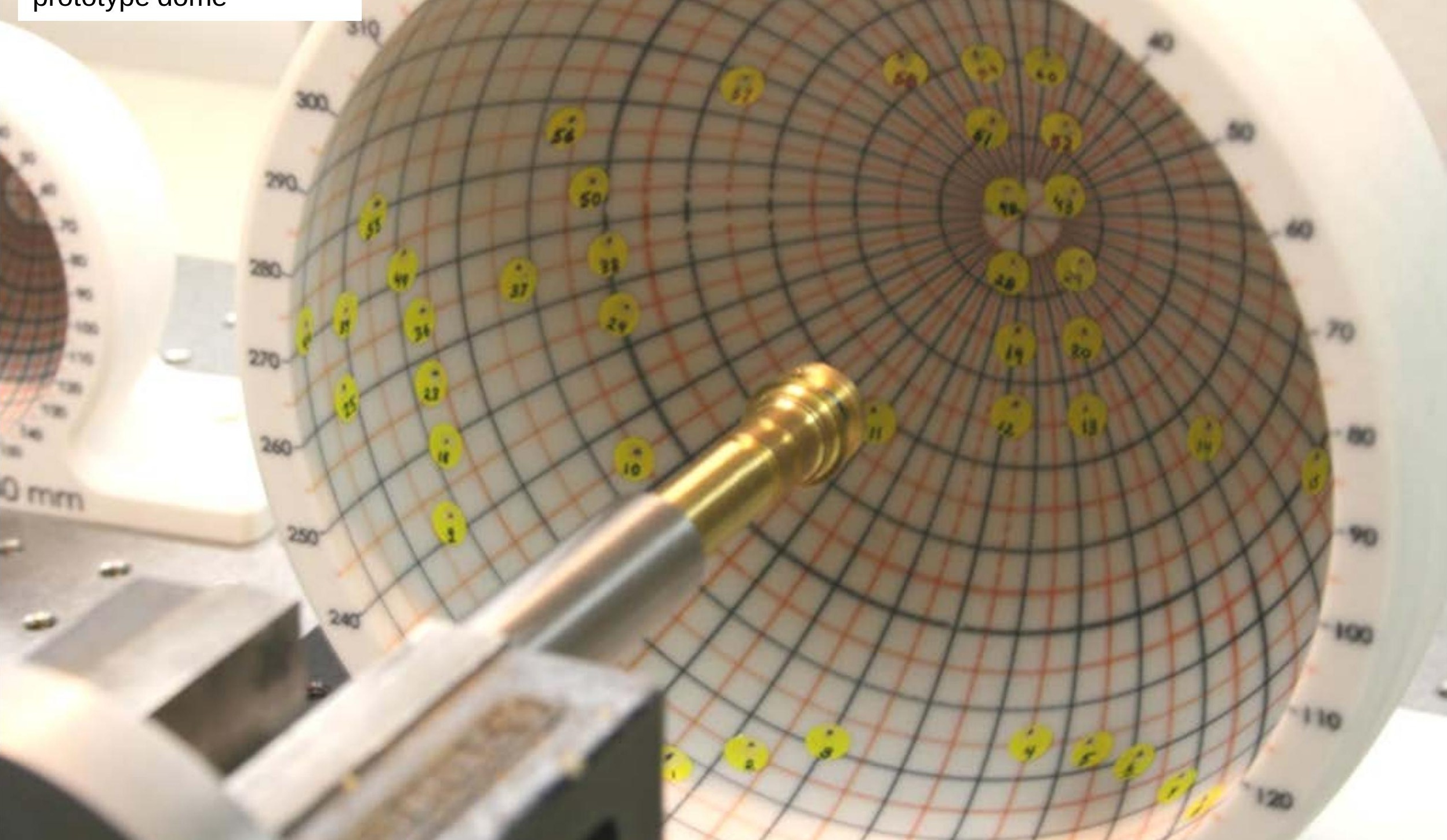




\section{Example Channel Map of 216 Points}

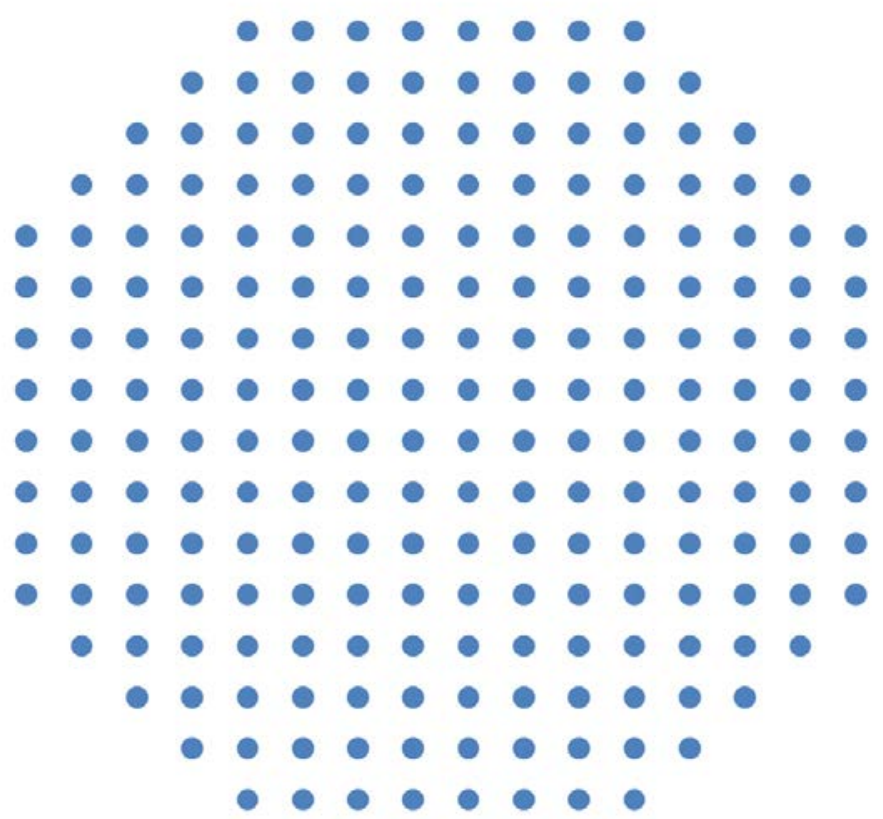




\section{Lens Design Changes}
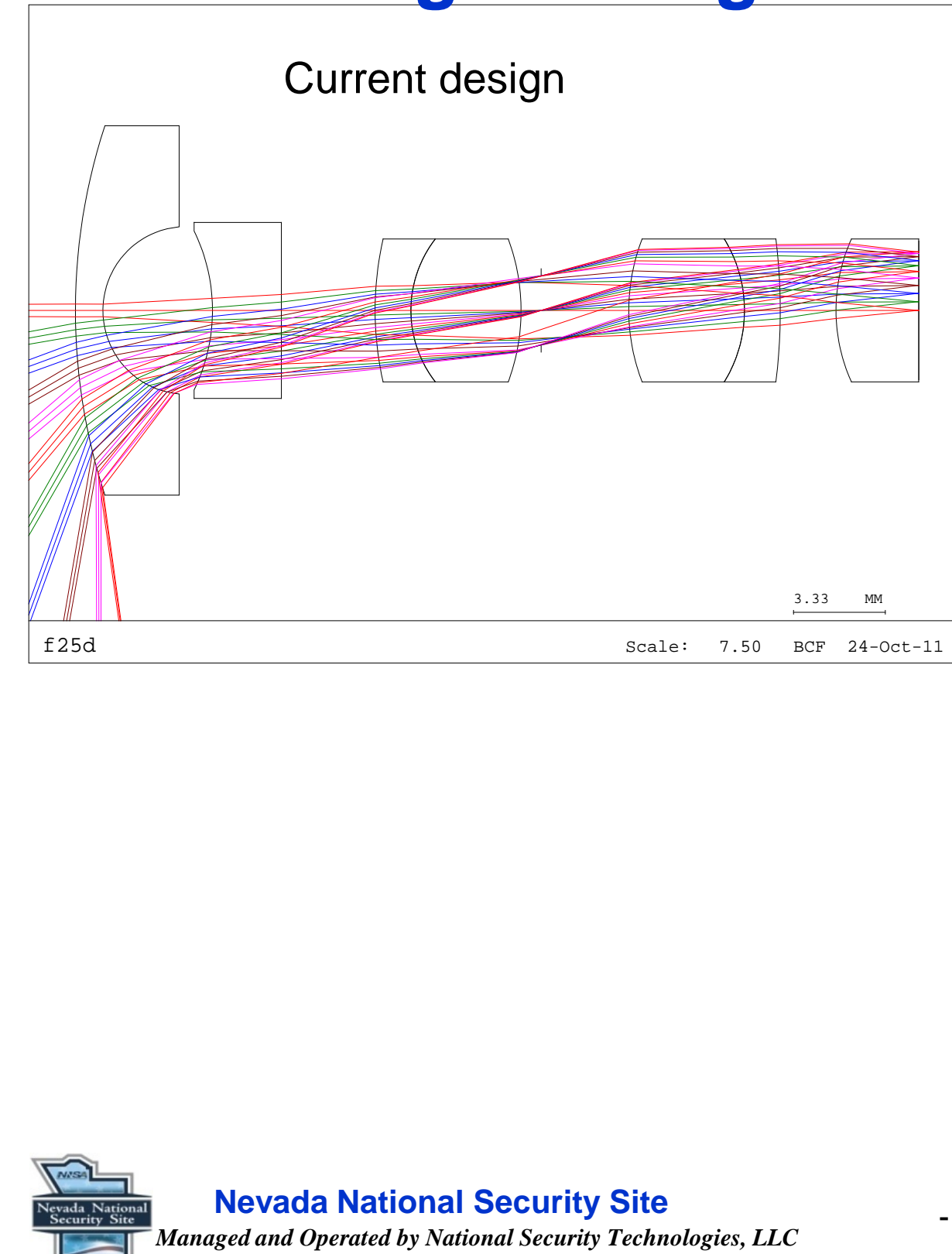

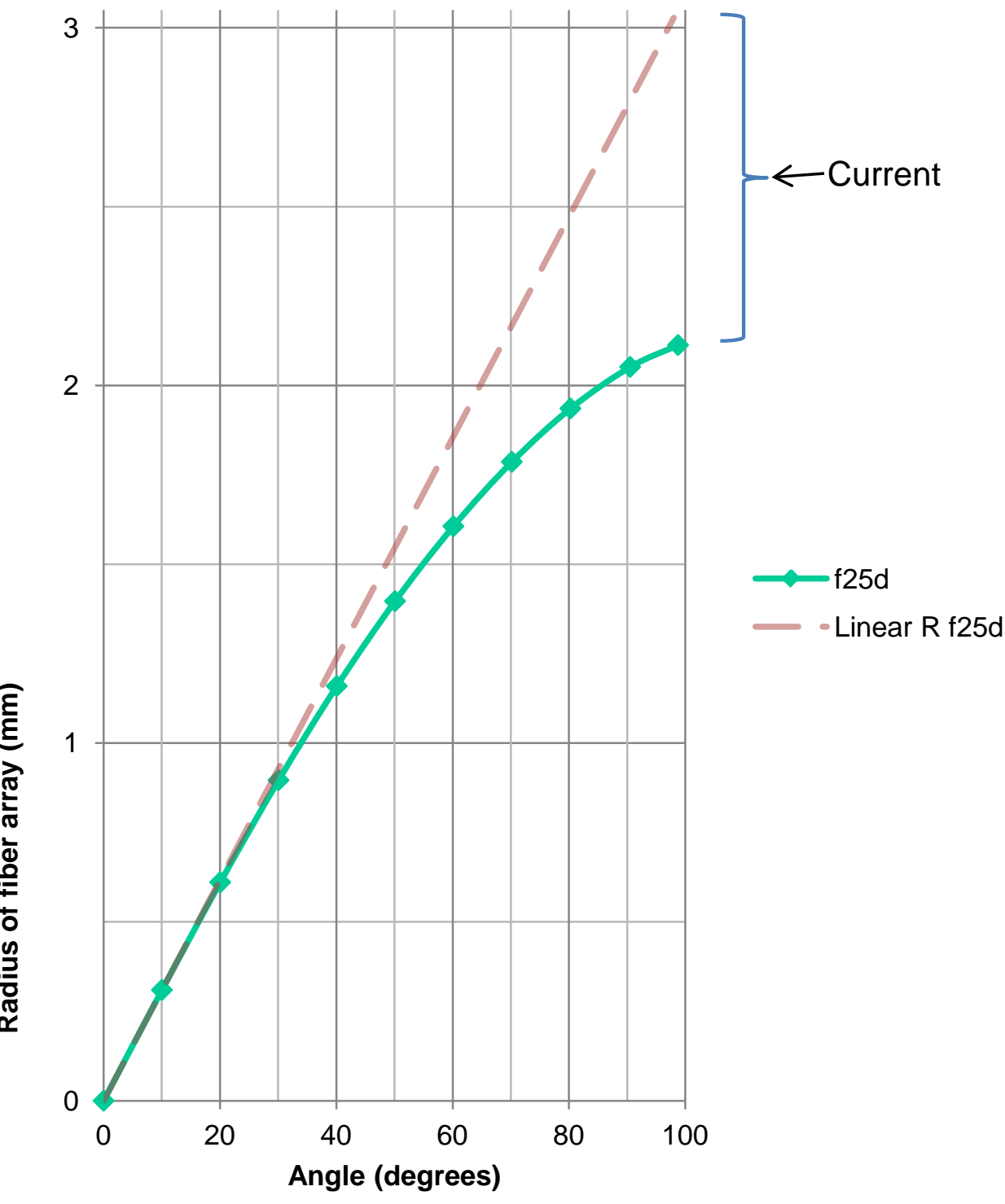

National Security Technologies LLC
- Los Alamos National laboratony 


\section{Lens Design Changes}

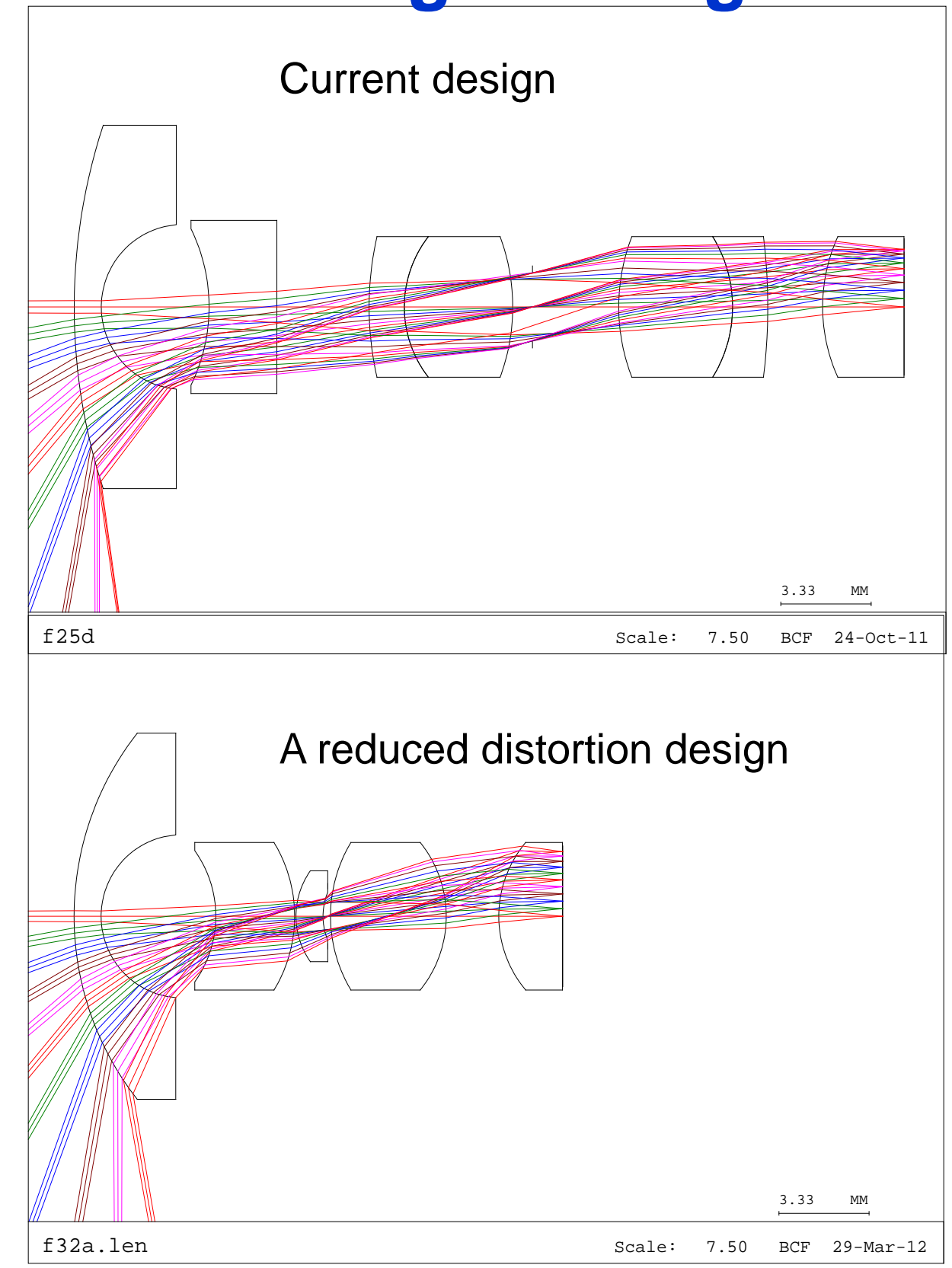

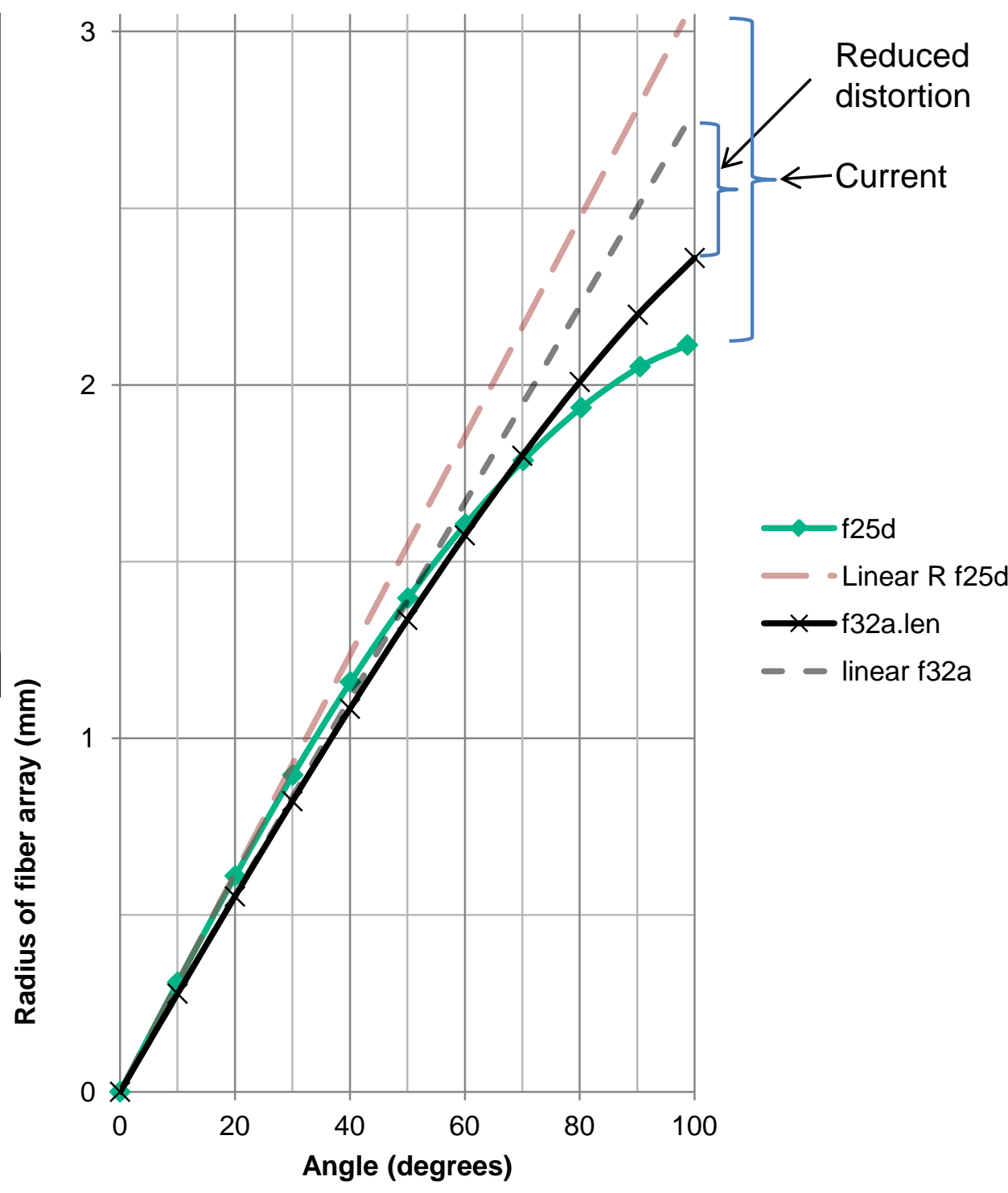

-20- Los Alamos therora 


\section{Projected Fiber Spots on Hemisphere}
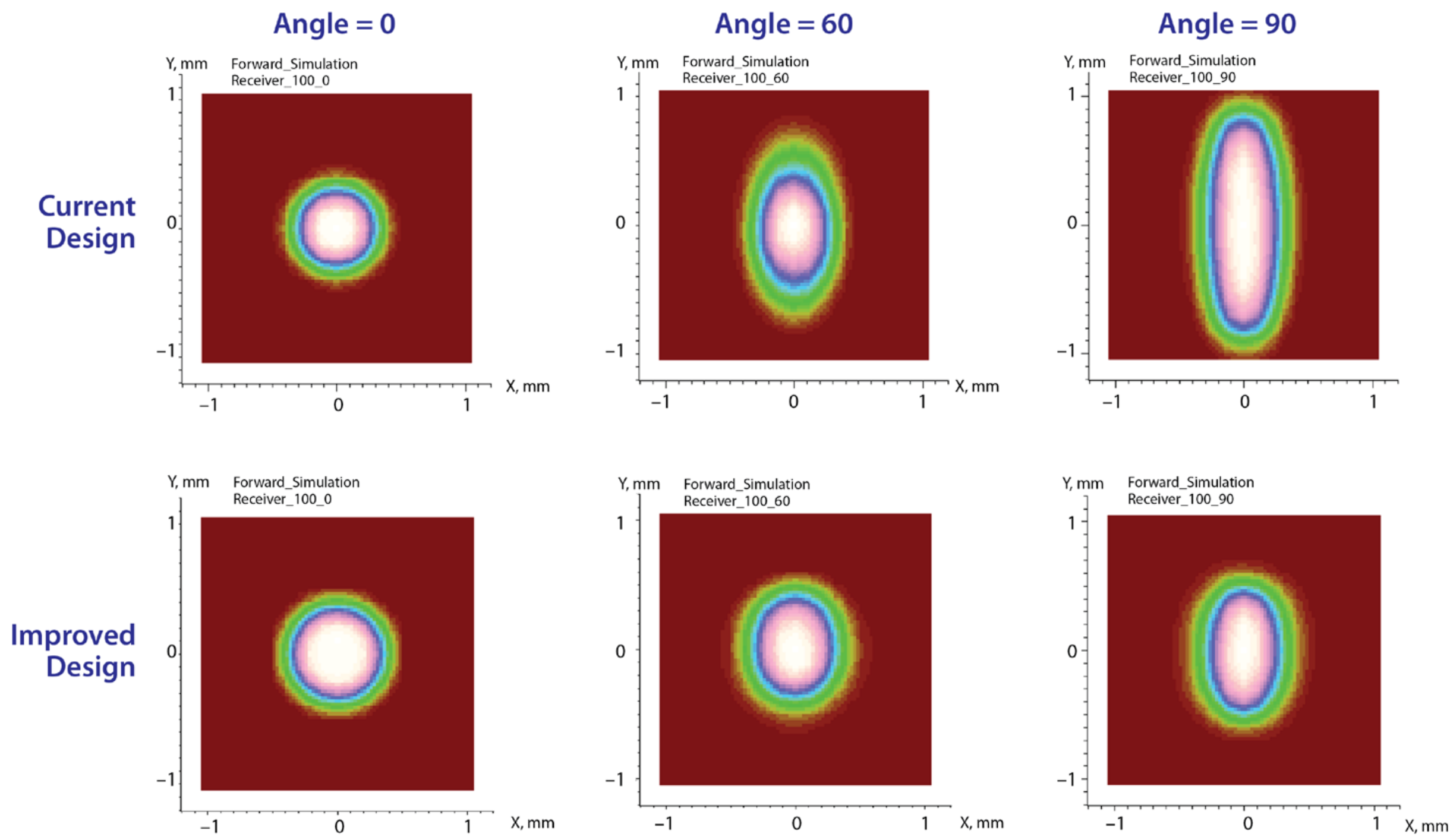


\section{Fisheye Lens PDV Probe Summary}

- Long tracking distance (probe is small)

- Large angle coverage: $\sim \pm 100$ degrees (dome)

- Index-matching element

- Reduces return loss

- Flattens field and makes light telecentric into and out of fibers

- Eases assembly

- Uses glues and index-matching gel (sealed inside)

- Includes many spare fibers (measurement points)

- Point positions adjusted by changing custom fiber ferrule

- (can use smaller cladding fibers for closer spacings) 